\title{
Application of Grain Boundary Engineering to Improve Intergranular Corrosion Resistance in a Fe-Cr-Mn-Mo-N High-Nitrogen and Nickel-Free Austenitic Stainless Steel
}

\author{
Feng Shi ${ }^{1} \cdot$ Ruo-Han Gao ${ }^{1}$ Xian-Jun Guan ${ }^{1}$. Chun-Ming Liu² $\cdot$ Xiao-Wu Li ${ }^{1,2}$ \\ Received: 6 September 2019 / Revised: 7 November 2019 / Published online: 14 January 2020 \\ (c) The Chinese Society for Metals (CSM) and Springer-Verlag GmbH Germany, part of Springer Nature 2020
}

\begin{abstract}
Optimization of grain boundary engineering (GBE) process is explored in a $\mathrm{Fe}-20 \mathrm{Cr}-19 \mathrm{Mn}-2 \mathrm{Mo}-0.82 \mathrm{~N}$ high-nitrogen and nickel-free austenitic stainless steel, and its intergranular corrosion (IGC) property after GBE treatment is experimentally evaluated. The proportion of low $\Sigma$ coincidence site lattice (CSL) boundaries reaches $79.4 \%$ in the sample processed with $5 \%$ cold rolling and annealing at $1423 \mathrm{~K}$ for $72 \mathrm{~h}$; there is an increase of $32.1 \%$ compared with the solution-treated sample. After grain boundary character distribution optimization, IGC performance is noticeably improved. Only $\Sigma 3$ boundaries in the special boundaries are resistant to IGC under the experimental condition. The size of grain cluster enlarges with increasing fraction of low $\Sigma$ CSL boundaries, and the amount of $\Sigma 3$ boundaries interrupting the random boundary network increases during growth of the clusters, which is the essential reason for the improvement of IGC resistance.
\end{abstract}

Keywords High-nitrogen and nickel-free austenitic stainless steel $\cdot$ Grain boundary engineering $\cdot$ Electron backscatter diffraction (EBSD) $\cdot$ Low $\Sigma$ coincidence site lattice boundary $\cdot$ Intergranular corrosion

\section{Introduction}

The notion of "Grain Boundary Design and Control" was first put forward by Watanabe [1] in 1984 and later developed into the well-known "grain boundary engineering (GBE)" [2]. Watanabe [1] pointed out that increasing the fraction of grain boundaries (GBs) with special properties in grain boundary character distribution (GBCD) would enhance the GB-related performances, especially the resistance to intergranular corrosion (IGC).

In recent years, GBE, also known as GBCD optimization, has received extensive attention in solving the problems of IGC [3-9] and other GB failures [10-14]. Shimada et al. [3]

Available online at http://link.springer.com/journal/40195.

Xiao-Wu Li

xwli@mail.neu.edu.cn

1 Department of Materials Physics and Chemistry, School of Materials Science and Engineering, Northeastern University, Shenyang 110819, China

2 Key Laboratory for Anisotropy and Texture of Materials (Ministry of Education), Northeastern University, Shenyang 110819, China reported that the fraction of special boundaries ( $\mathrm{SBs}$ ), that is, low $\Sigma$ coincidence site lattice (CSL) boundaries, reached $85 \%$ in the 304 austenitic stainless steel (ASS) through an annealing treatment at $1200 \mathrm{~K}$ for $72 \mathrm{~h}$ after $5 \%$ cold-rolling deformation. Michiuchi et al. [4] applied a similar process to 316 ASS, and the fraction of low $\Sigma$ CSL boundaries achieved 86\%. After GBCD optimization, the IGC resistances of the two ASSs were significantly improved.

In a new type of ASS, e.g., high-nitrogen and nickel-free ASS, Ni is replaced by a combination of $\mathrm{Mn}$ and $\mathrm{N}$, which not only saves cost but also exhibits an excellent comprehensive performance [15-18]; however, the precipitation of nitride may occur at GBs during hot working [19-22], which causes IGC of the new type of ASS [23-26]. To the best of our knowledge, there are still very few reports on the application of GBE to this advanced steel [9, 27, 28]. Our previous work reported that the proportion of SBs reached $83.3 \%$ through an annealing treatment at $1423 \mathrm{~K}$ for $10 \mathrm{~min}$ after 7\% cold-rolling deformation and the IGC resistance was significantly improved in a $\mathrm{Fe}-\mathrm{Cr}-\mathrm{Mn}-\mathrm{N}$ high-nitrogen and nickel-free ASS [9]. Thus, it is recognized that GBE can be applied to high-nitrogen ASS to solve the problem of GB failure caused by the precipitation of nitrides. 
The addition of Mo element to $\mathrm{Fe}-\mathrm{Cr}-\mathrm{Mn}-\mathrm{N}$ steel can significantly improve local corrosion performance of steel, especially pitting corrosion resistance [29, 30]; however, the addition of Mo may cause the precipitation of intermetallic phases in addition to nitrides during hot working [19]. These two kinds of precipitates at GBs will cause severe IGC in $\mathrm{Fe}-\mathrm{Cr}-\mathrm{Mn}-\mathrm{Mo}-\mathrm{N}$ high-nitrogen and nickel-free ASS. The work by Kokawa et al. [27] indicated that the proportion of SBs reached $87 \%$ through an annealing treatment at $1423 \mathrm{~K}$ for $48 \mathrm{~h}$ after $2 \%$ cold-rolling deformation and the precipitation was inhibited in the welding heat-affected zone in a $\mathrm{Fe}-\mathrm{Cr}-\mathrm{Ni}-\mathrm{Mo}-\mathrm{N}$ high-nitrogen ASS. Based on the above results, it can be deduced that the GBE optimization process should be different in the high-nitrogen steels with different compositions. Changes in elements may cause the differences in GBE optimization process and the relevant mechanism for IGC improvement. The present work explores GBE technology and evaluates IGC property after GBE process optimization in a $\mathrm{Fe}-\mathrm{Cr}-\mathrm{Mn}-\mathrm{Mo}-\mathrm{N}$ high-nitrogen and nickel-free ASS in order to further probe the feasibility of the GBE method applying to the advanced material to improve its IGC resistance, and thus provide a theoretical basis for the low-cost and large-scale practical application of the resource-saving ASS.

\section{Experimental}

The high-nitrogen and nickel-free Fe-20Cr-19Mn-2Mo-0.82 N (wt\%) ASS was used in this study, and the specific chemical composition is listed in Table 1. The cold-rolled plates were solution-treated at $1323 \mathrm{~K}$ for $1 \mathrm{~h}$ and then water-quenched (WQ). Hereafter, these samples are called the base materials (BMs). The BMs were deformed, respectively, to $3,5,7$ and $10 \%$ by cold rolling followed by annealing at $1423 \mathrm{~K}$ for $10 \mathrm{~min}$ or $72 \mathrm{~h}$ in vacuum atmosphere and then WQ. These samples were characterized using the electron backscatter diffraction (EBSD) in the JEOL JSM 7001F field emission scanning electron microscope (FESEM) equipped with an orientation imaging microscopy (OIM) system. Before EBSD measurement, each sample was mechanically ground and then electropolished in a solution of $8 \mathrm{vol} \%$ perchloric acid to ethanol at $30 \mathrm{~V}$ for $15 \mathrm{~s}$. EBSD analysis with the step size of $1.0 \mu \mathrm{m}$ was performed in the no less than $1000 \mu \mathrm{m} \times 1000 \mu \mathrm{m}$ analyzed area to ensure the statistical significance. The average grain size is estimated from the EBSD-reconstructed images. The fractions of the different grain boundary types were determined on the basis of the length fraction by dividing the number of pixels of a particular boundary by that of the entire GBs. GBs with $\sum \leq 29$ were denoted as the low $\Sigma C S L$ boundaries (SBs) [1, 2], and Brandon criterion was adopted to categorize the CSL boundaries with low energy [31]. All samples were sensitization-treated at $1123 \mathrm{~K}$ for $2 \mathrm{~h}$ and WQ to induce the precipitation of nitrides and intermetallic phases at GBs [19, 20, 32]. The oxalic acid electrochemical corrosion and ferric sulfate-sulfuric acid tests were adopted to evaluate the IGC property of the experimental steel after GBE and sensitization treatments. The oxalic acid electrochemical corrosion test was performed in a $10 \%$ oxalic acid solution at $1 \mathrm{~A} / \mathrm{cm}^{2}$ for $90 \mathrm{~s}$. After oxalic acid electrochemical corrosion, the microstructures of the samples were observed by Olympus GX 71 optical microscopy (OM) and the corresponding EBSD was measured using FESEM. The BM- and GBE-treated samples were assessed by ferric sulfate-sulfuric acid test $[5,33]$. The size, surface area and weight of BM- and GBE-treated samples were firstly measured, and then, they were immersed into a boiling solution of $6.8 \mathrm{~mol} / \mathrm{L} \mathrm{H}_{2} \mathrm{SO}_{4}$ plus $0.1 \mathrm{~mol} / \mathrm{L} \mathrm{Fe}_{2}\left(\mathrm{SO}_{4}\right)_{3}$ for different time periods (24-72 h). After each corrosion test, the specimens were taken out for cleaning and drying, and subsequently remeasured and reweighed to obtain percolation depth, weight loss and corrosion rate at different immersing times $[5,33]$. The microstructures of the tested samples were observed by FESEM.

\section{Results}

\subsection{Exploration of GBE Process}

The fractions of CSL boundaries for the BM- and GBEtreated samples are listed in Table 2. According to the data in Table 2, the histogram of the fraction of SBs $\left(f_{\mathrm{SBs}}\right)$ under different heat treatment conditions is drawn in Fig. 1. From Fig. 1 and Table 2, it can be seen that the $f_{\text {SBs }}$ of the GBE-treated sample is all higher than that of the $\mathrm{BM}$. The $f_{\mathrm{SBs}}$ of the sample annealed for a long time (72 $\mathrm{h}$ ) is higher than that of short-time (10 $\mathrm{min})$ sample under each cold-rolling reduction, and the highest $f_{\mathrm{SBs}}$ appears in the sample annealed at $1423 \mathrm{~K}$ for $72 \mathrm{~h}$ after cold rolling by $5 \%$ reduction (herein called $\mathrm{r} 5 \%$-a $1423 \mathrm{~K} / 72 \mathrm{~h}$ for short) and reaches $79.4 \%$ for the experimental steel. However, the result is different from that in the $\mathrm{Fe}-18 \mathrm{Cr}-18 \mathrm{Mn}-0.63 \mathrm{~N}$ ASS. In the $\mathrm{Fe}-18 \mathrm{Cr}-18 \mathrm{Mn}-0.63 \mathrm{~N}$ steel, the $f_{\mathrm{SBs}}$ of the short-time annealed sample is basically higher than that of
Table 1 Chemical composition of the experimental steel (wt\%)

\begin{tabular}{lllllllll}
\hline $\mathrm{Cr}$ & $\mathrm{Mn}$ & $\mathrm{Mo}$ & $\mathrm{N}$ & $\mathrm{C}$ & $\mathrm{S}$ & $\mathrm{P}$ & $\mathrm{Al}$ & $\mathrm{Fe}$ \\
\hline 20.17 & 19.10 & 2.29 & 0.82 & 0.065 & 0.0025 & 0.0017 & 0.04 & Bal. \\
\hline
\end{tabular}


Table 2 Proportions of various SBs for the BM and those samples after cold rolling at different thickness reductions and annealing at $1423 \mathrm{~K}$ for $10 \mathrm{~min}$ and $72 \mathrm{~h}$

\begin{tabular}{lllll}
\hline GBE treatment process & $\sum 3(\%)$ & $\sum 9+\sum 27(\%)$ & $\begin{array}{l}\text { Other low CSL grain } \\
\text { boundaries }(\%)\end{array}$ & Total SBs (\%) \\
\hline Solid solution $(\mathrm{BM})$ & 43.8 & 1.1 & 2.4 & 47.3 \\
r3\%-a1423K/10 min & 45.7 & 1.4 & 2 & 49.1 \\
r5\%-a1423K/10 min & 49.9 & 1.3 & 2.2 & 53.4 \\
r7\%-a1423K/10 min & 60.9 & 8.1 & 1.1 & 70.1 \\
r10\%-a1423K/10 min & 53.2 & 6.5 & 1.9 & 61.6 \\
r3\%-a1423K/72 h & 46.6 & 5.3 & 1.5 & 53.4 \\
r5\%-a1423K/72 h & 74.0 & 5.2 & 0.2 & 79.4 \\
r7\%-a1423K/72 h & 60.5 & 8.8 & 0.9 & 70.3 \\
r10\%-a1423K/72 h & 58.6 & 3.4 & 2.6 & 64.6 \\
\hline
\end{tabular}

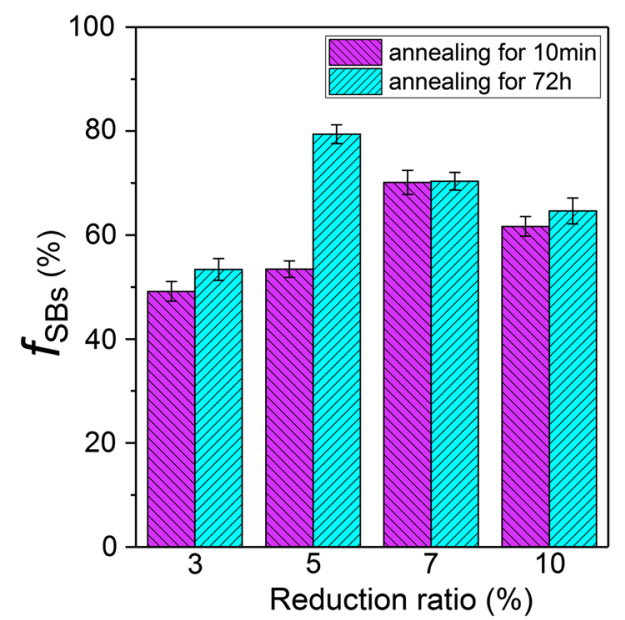

Fig. 1 Effects of cold-rolling reduction and annealing time on the fraction of SBs in the $\mathrm{Fe}-20 \mathrm{Cr}-19 \mathrm{Mn}-2 \mathrm{Mo}-0.82 \mathrm{~N}$ high-nitrogen and nickel-free ASS long-time annealed sample after cold rolling with different deformation and the highest $f_{\mathrm{SBs}}$ of $83.3 \%$ occurred under the condition of annealing at $1423 \mathrm{~K}$ for $10 \mathrm{~min}$ after cold rolling by $7 \%$ reduction $[9,28]$.

The GBCDs of the BM are shown in Fig. 2. The $f_{\mathrm{SB}}$ is determined to be $47.3 \%$ in the BM (Table 2), and the connectivity of the random boundary network is relatively complete, as shown in Fig. $2 b$.

The GBCDs of low $\Sigma$ CSL boundaries and random boundaries for the samples after GBE process treatment are shown in Fig. 3. During GBCD optimization, the grain cluster is often mentioned by the investigators [5, 7, 9]. The grain cluster is referred to such a grain encircled by the random boundary containing a large amount of SBs inside [7, 9]. After GBCD optimization, the large-sized grain clusters become typical microstructures of the samples $[5,7,9,34]$. As seen in Fig. 3, the larger the size of the grain cluster is, the better the optimization effect is. The size of grain cluster is the largest in the $55 \%$ a1423K/72 h sample owning the highest $f_{\mathrm{SBs}}$ (Fig. 3d).
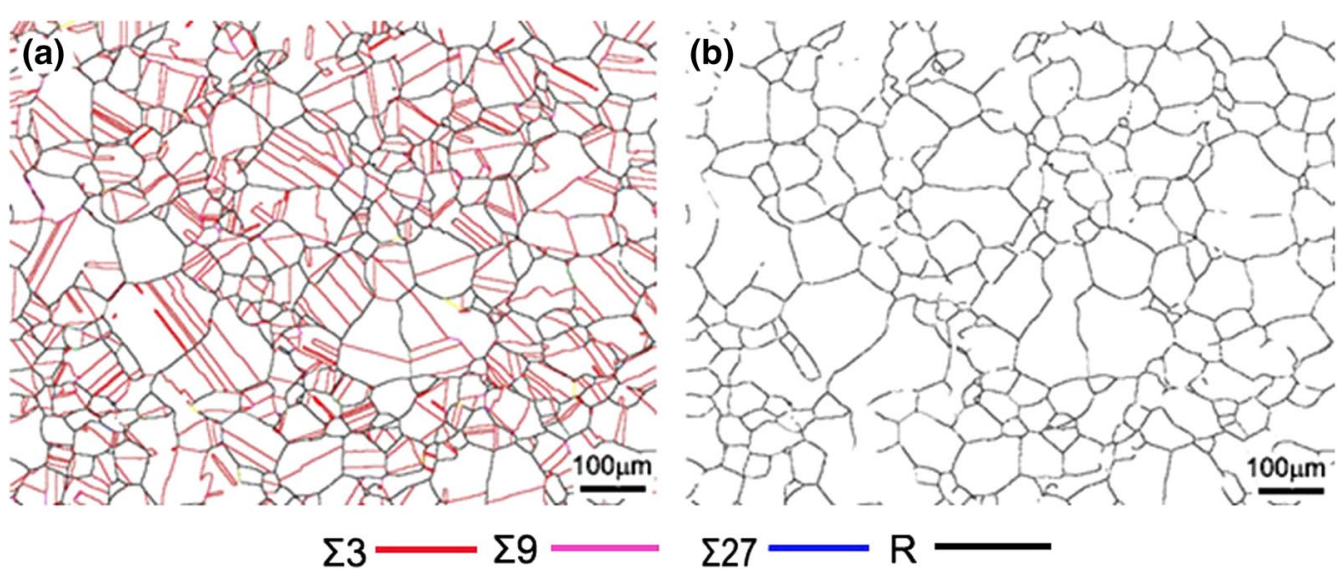

Fig. 2 EBSD-reconstructed images of SBs and random boundaries in the BM: a GBCD of SBs and random boundaries, $\mathbf{b}$ GBCD of random boundaries 


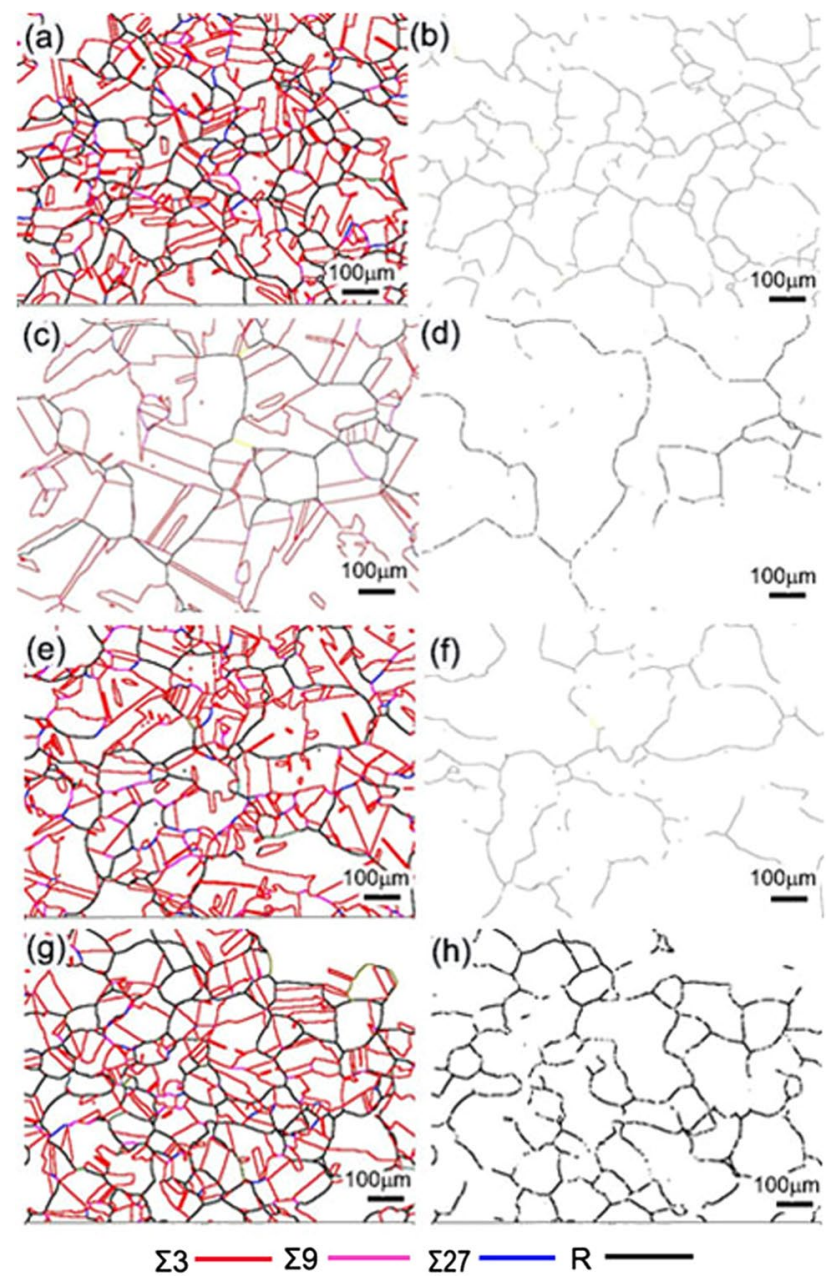

Fig. 3 EBSD-reconstructed images of SBs and random boundaries under different GBE treatment conditions: $\mathbf{a}$ and $\mathbf{b} \mathrm{r} 3 \%$-a $1423 \mathrm{~K} / 72 \mathrm{~h}$, c and d r5\%-a1423K/72 h, e and f r7\%-a1423K/72 h, g and h r10\%a1423K/72 h

\subsection{Influence of GBE Process Optimization on the IGC Resistance}

To study the relationship between GBE process optimization and IGC resistance in the $\mathrm{Fe}-\mathrm{Cr}-\mathrm{Mn}-\mathrm{Mo}-\mathrm{N}$ experimental steel, the BM with the lowest $f_{\mathrm{SBs}}(47.3 \%)$, the r10\%a1423K/72 h sample with the moderate $f_{\mathrm{SBs}}(64.6 \%)$ and the $\mathrm{r} 5 \%$-a $1423 \mathrm{~K} / 72 \mathrm{~h}$ sample with the highest $f_{\mathrm{SBs}}(79.4 \%)$ are selected for IGC performance tests.

The experimental results after oxalic acid electrolytic corrosion in these three samples are presented in Fig. 4. From Figure $4 \mathrm{a}$, it can be seen that the corrosion grooves of GBs are wide and IGC is rather serious in the BM. Apparently, the IGC resistances become better in the samples after GBE process optimization. IGC extent is the lightest in the r5\%a1423K/72 h sample (Fig. 4b). Therefore, it can be concluded that the IGC extent, $f_{\mathrm{SBs}}$ and the size of grain cluster are one-to-one correspondence. That is to say, the sample with the higher $f_{\mathrm{SBs}}$ owns the larger grain-cluster size and the better IGC resistance.

Figures 5 and 6 show, respectively, SEM results of the surface and cross section of these three samples after the ferric sulfate-sulfuric acid test for different times. After immersing for $24 \mathrm{~h}$, grain dropping is very severe and less surface grains remained in the BM (Figs. 5a, 6a). However, the surfaces still keep complete and GBs are just beginning to be corroded in the samples after GBE process optimization (Fig. 5b, c). Only the corrosion remains on the surface in the r5\%-a1423K/72 h sample (Fig. 6c), while IGC has started to penetrate into the interior in the r10\%-a1423K/72 h sample (Fig. 6b). After immersing for $48 \mathrm{~h}$, the surface grains of the BM have completely peeled off (Figs. 5d, 6d), whereas grains have partially dropped in the $\mathrm{r} 10 \%$-a $1423 \mathrm{~K} / 72 \mathrm{~h}$ sample (Figs. 5e, 6e), and the surface layer still keep basically integrated (Fig. 5f) and IGC begins to penetrate into the interior (Fig. 6f) in the r5\%-a1423K/72 h sample. After immersing for $72 \mathrm{~h}$, the extent and depth of grain dropping gradually increase in
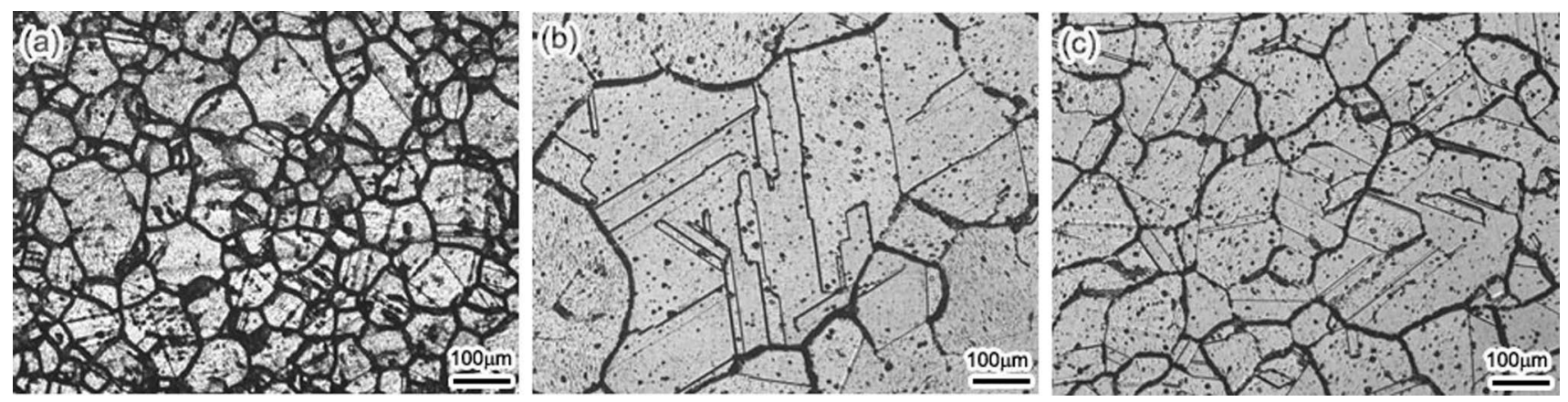

Fig. 4 Optical micrographs of oxalic acid electrolytic corrosion after sensitizing at $1123 \mathrm{~K}$ for $2 \mathrm{~h}$ in the different samples: a BM, b r5\%a1423K/72 h, c r10\%-a1423K/72 h 


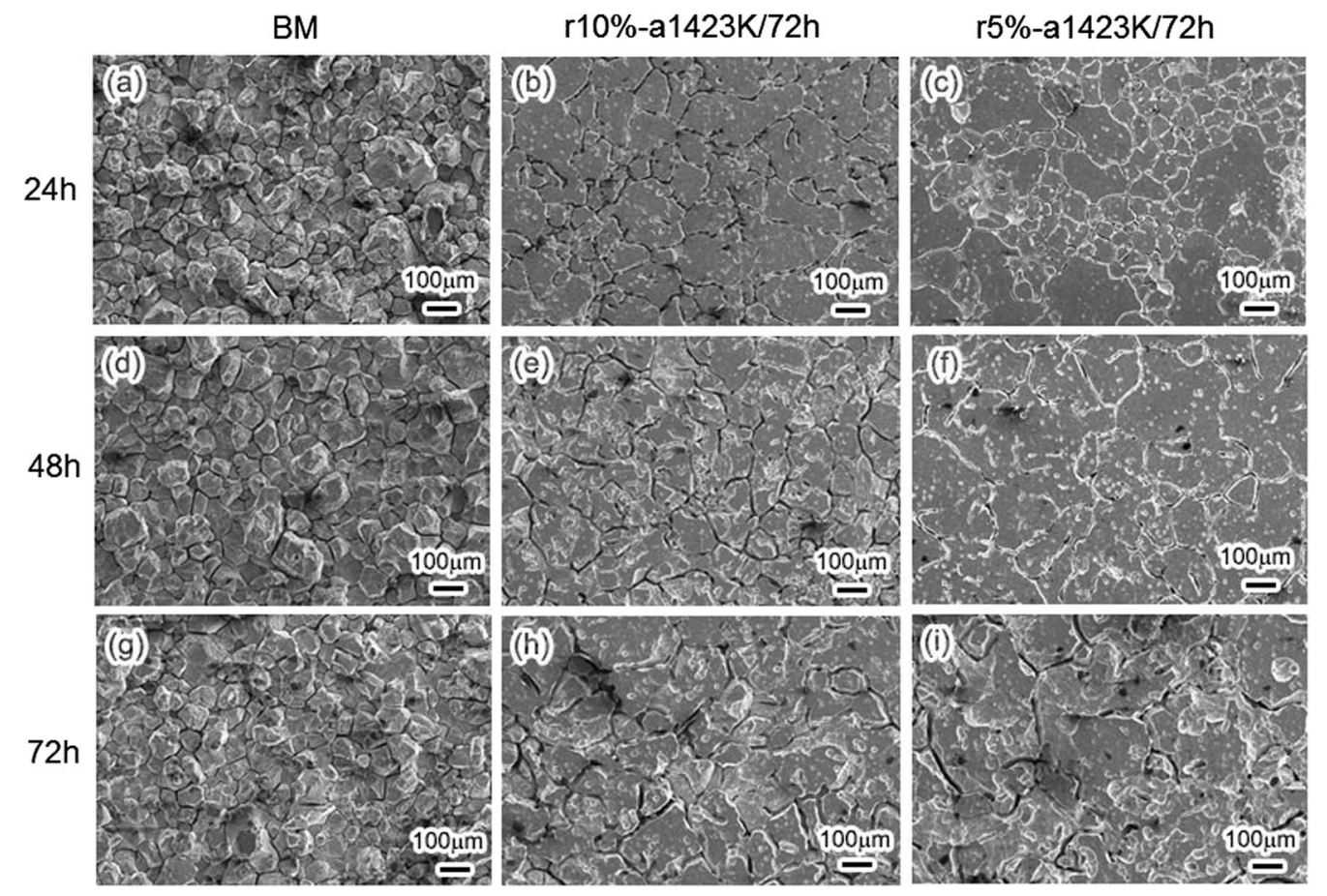

Fig. 5 SEM images of the surfaces in the BM, r10\%-a1423K/72 $\mathrm{h}$ and r5\%-a1423K/72 $\mathrm{h}$ samples after $24 \mathrm{~h}, 48 \mathrm{~h}$ and $72 \mathrm{~h}$ ferric sulfate-sulfuric acid corrosion tests
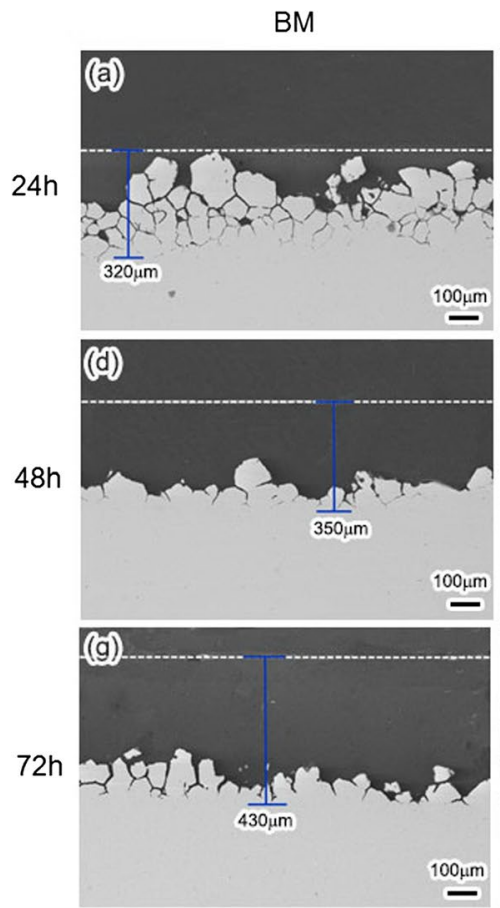

$r 10 \%-a 1423 K / 72 h$

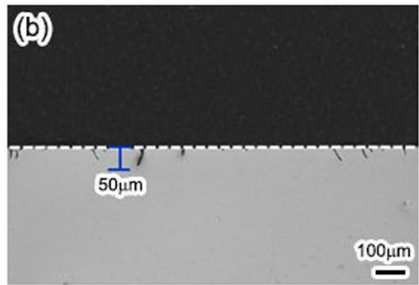

(ê)
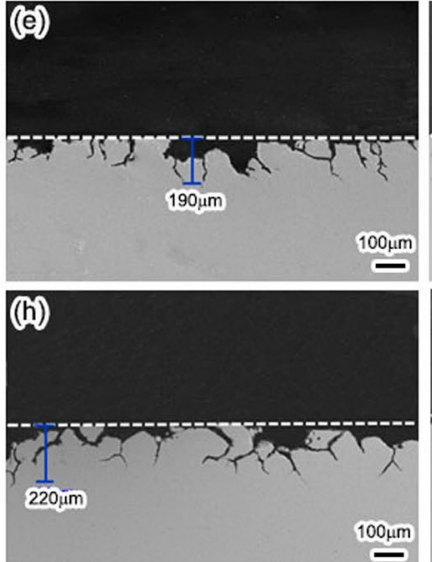

$\mathrm{r} 5 \%-\mathrm{a} 1423 \mathrm{~K} / 72 \mathrm{~h}$
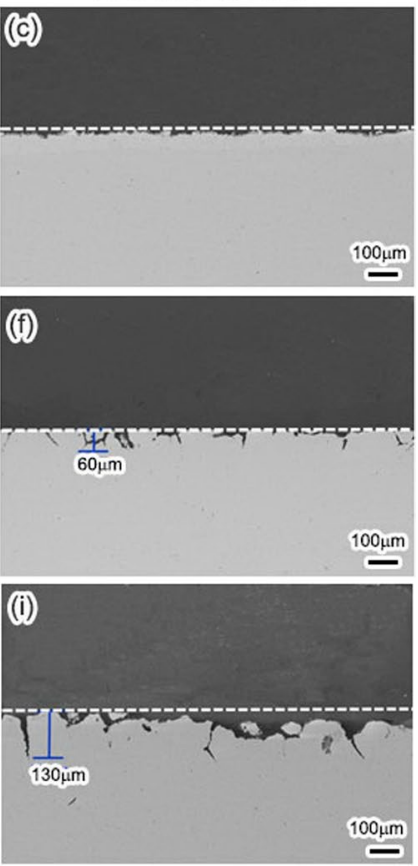

Fig. 6 SEM images of the cross sections in the BM, r10\%-a1423K/72 h and r5\%-a1423K/72 h samples after $24 \mathrm{~h}, 48 \mathrm{~h}$ and $72 \mathrm{~h}$ ferric sulfatesulfuric acid corrosion tests 
the BM (Figs. 5g, 6g). The surface grain continues to fall off in the r10\%-a1423K/72 h sample (Figs. 5h, 6h). The GB corrosion becomes more serious, and surface grain also begins to fall off in the $\mathrm{r} 5 \%$-a $1423 \mathrm{~K} / 72 \mathrm{~h}$ sample (Figs. 5i, 6i). Figure 6 displays the variety of percolation depth with immersing time in these three samples. As the immersing time increases, the percolation depths increase in all samples; however, regardless of the test time, the percolation depth is the lowest for the $\mathrm{r} 5 \%$-a1423K/72 $\mathrm{h}$ sample but the highest for the $\mathrm{BM}$. According to the above experimental results, it can be observed that there is a negative correlation between the change in percolation depth and the $f_{\mathrm{SBs}}$.

Figures 7 and 8 show, respectively, the varieties of weight loss and corrosion rate with the change of corrosion duration after ferric sulfate-sulfuric acid test in these three samples. The weight loss and corrosion rate both increase as the corrosion time increases in each sample, but no matter what the corrosion duration is, the weight loss is the greatest and corrosion rate is the fastest in the $\mathrm{BM}$ and the weight loss is the least and corrosion rate is the slowest in the $\mathrm{r} 5 \%$-a $1423 \mathrm{~K} / 72 \mathrm{~h}$ sample. The weight loss and corrosion rate of the $\mathrm{r} 10 \%$-a $1423 \mathrm{~K} / 72 \mathrm{~h}$ sample are about $45 \%$ of the BM, but the relevant values of the r5\%-a1423K/72 h sample are only $19 \%$ of the BM, when the test time is $72 \mathrm{~h}$. According to the above experimental results, it can be seen that the changes in weight loss, the corrosion rate and the $f_{\mathrm{SBs}}$ are also one-to-one correspondence. Therefore, the comparisons of percolation depth, weight loss, corrosion rate and $f_{\mathrm{SBs}}$ in the samples further demonstrate a quite beneficial effect of GBE process optimization on the IGC improvement in the experimental steel.

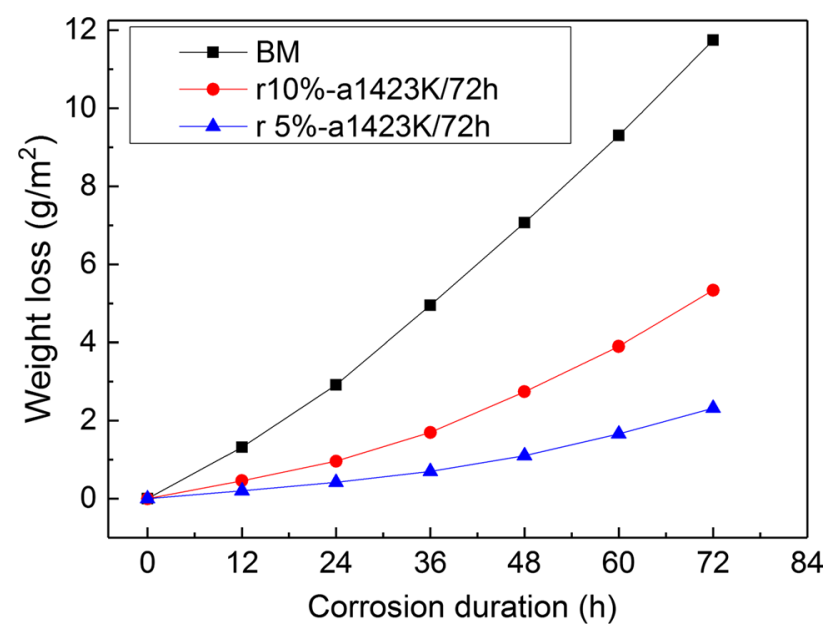

Fig. 7 Comparison of weight loss versus corrosion duration curves for the BM, r10\%-a1423K/72 $\mathrm{h}$ and r5\%-a1423K/72 h samples

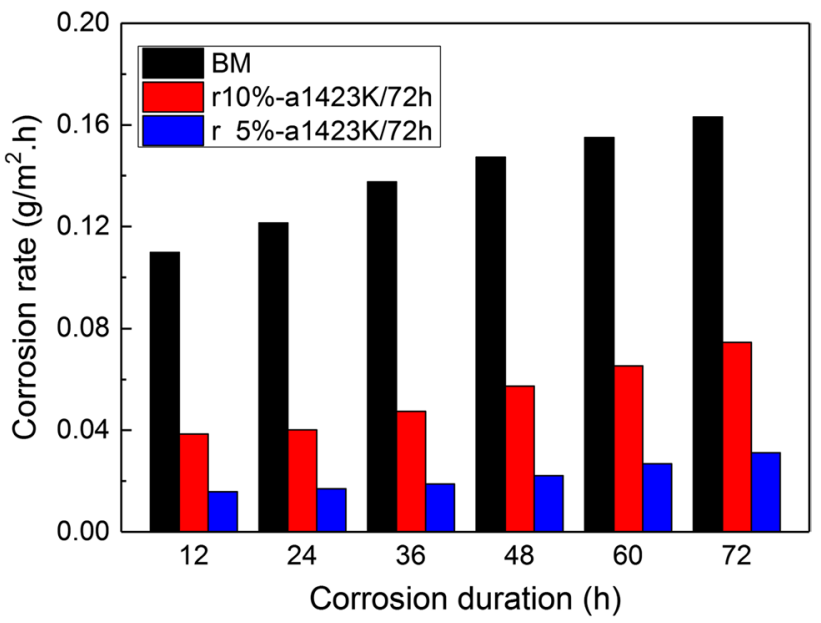

Fig. 8 Comparison of the corrosion rate in the BM, r10\%a $1423 \mathrm{~K} / 72 \mathrm{~h}$ and $\mathrm{r} 5 \%$-a1423K/72 $\mathrm{h}$ samples during ferric sulfate-sulfuric acid corrosion tests

\section{Discussion}

As a new method to improve IGC resistance, GBE has been applied in 304 ASS [3, 5], 316 ASS [4], Alloy 690 [7], high-nitrogen ASS [9], etc. Although the GBCD optimization mechanism induced by annealing twins (ATs) is still a debatable point, most of the researchers agreed that the grain clusters [7, 9, 34] or twin-related domains (TRD) [35, 36] are a basic feature of GBCD optimization. The higher the $f_{\mathrm{SBs}}$ is, the larger the size of the grain cluster is (Fig. 3). $\sum 3$ boundaries, namely AT boundaries, are the main components of SBs (Table 2). Therefore, the increase in $f_{\mathrm{SBs}}$ is mainly due to the increase in AT boundaries accompanying the growth of grain clusters during annealing. Some studies have indicated that ATs are mostly produced during recrystallization [37, 38]. Our recent work [39] demonstrated that the deformation microstructure will play a key role in the formation of ATs during subsequent annealing and stacking faults (SFs) are beneficial to the GBCD optimization, for which the formation of ATs can be induced by generating "stacking accidents" in a sequence of closely packed atomic planes at the front end of growing grain cluster. On the contrary, deformation twins (DTs) hinder the growth of the grain cluster, thus impairing GBCD optimization. In other words, the deformation microstructure owning a large number of SFs without DTs is desirable. Therefore, in order to obtain a high proportion of AT, the right amount of deformation is fairly critical, while the appropriate amount of deformation is closely related to the stacking fault energy (SFE) [40, 41]. In Fe-18Cr-18Mn-0.63 N steel, due to its low SFE, a large number of SFs can appear in the deformed microstructure under the right amount of deformation (e.g., 7\%) to provide sufficient strain energy; meanwhile, a high 
annealing temperature can provide sufficient thermal energy, which makes the grain boundary migration velocity fast, and AT density increases rapidly inside the grain cluster [9]; accordingly, grain cluster quickly grows up to extreme dimensions. That is why the highest $f_{\mathrm{SBs}}$ is obtained under high-temperature and short-time annealing after a low strain deformation in $\mathrm{Fe}-18 \mathrm{Cr}-18 \mathrm{Mn}-0.63 \mathrm{~N}$ steel. In contrast, in the present $\mathrm{Fe}-20 \mathrm{Cr}-19 \mathrm{Mn}-2 \mathrm{Mo}-0.82 \mathrm{~N}$ steel, the highest proportion of SBs occurs under high-temperature and longtime annealing after a low strain deformation. In the austenitic steel, the addition of Mo element increases SFE [42], and the addition of $\mathrm{N}$ element can generally decrease SFE. However, Gavriljuk et al. [43] reported that, as the N content exceeded $\sim 0.5 \%$, the increase in $\mathrm{N}$ content will increase the $\mathrm{SFE}$ in the $\mathrm{Cr}-\mathrm{Mn}-\mathrm{N}$ high-nitrogen ASS. Therefore, totally speaking, the SFE of $\mathrm{Fe}-20 \mathrm{Cr}-19 \mathrm{Mn}-2 \mathrm{Mo}-0.82 \mathrm{~N}$ steel should be much higher than that of $\mathrm{Fe}-18 \mathrm{Cr}-18 \mathrm{Mn}-0.63 \mathrm{~N}$. For this reason, in the present steel, a low strain deformation cannot provide a sufficient strain energy, and a much higher thermal energy is thus needed for GBCD optimization by prolonging the time of subsequent annealing process. The formation of ATs actually includes two parts, i.e., one part appearing in the grain cluster is induced by SFs in the early stage of recrystallization, and the other part is formed by impingement of the growing clusters during prolonging annealing time [9, 34], which is the fundamental cause for the highest $f_{\mathrm{SBs}}$ obtained by high-temperature and long-time annealing in the experimental steel.

Regarding the mechanism of GBE method improving IGC resistance, the investigators generally thought that the grain clusters played a key role in the disconnection of the random boundaries, and the interrupting of the random boundary network by low $\Sigma$ CSL boundaries improved the IGC property [3, 5, 9]. As seen in Fig. 3, the grain clusters are formed in the BM, r10\%-a1423K/72 h and r5\%-a1423K/72 h samples. Figure 9 gives quantitatively the variations of the average grain size (twin included) and grain-cluster size with the fraction of low $\Sigma$ CSL boundaries in these three samples. It can be seen that the average grain size does not change much but the cluster size gradually increases as the $f_{\mathrm{SBs}}$ increases. In the $\mathrm{r} 5 \%$-a1423K/72 $\mathrm{h}$ sample with the highest $f_{\mathrm{SBs}}$, the size of grain cluster is the largest.

Although the view or appearance of interruption of the random boundaries by low $\sum$ CSL boundaries is consistent, the disconnection mechanism and interrupting effect of low $\sum$ CSL boundaries were reported to be distinctive in different materials. Specifically, concerning the disconnection mechanism, Tokita et al. [34] considered that disconnection of the random boundaries was achieved by the formation of the SBs through the impingement of the growing clusters during the thermo-mechanical process in the 304 ASS. In contrast, the research findings on the 304 ASS [3] and Fe-Cr-Mn-N ASS [9] demonstrated that

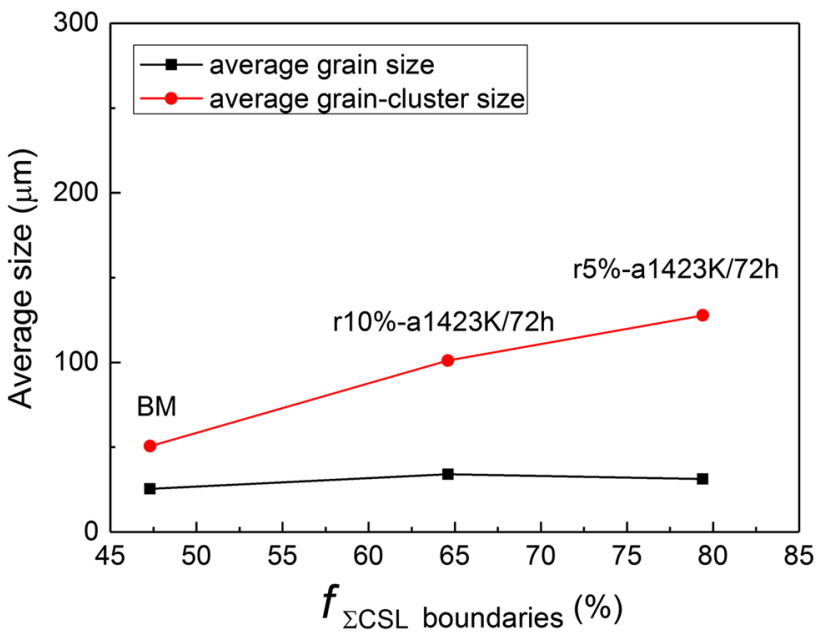

Fig. 9 Average grain size/grain-cluster size versus fraction of $\Sigma$ CSL boundaries curves for the BM, r10\%-a1423K/72 h and r5\%a1423K/72 h samples

the occurrence of annealing twins inside a grain cluster created the low-energy fragments of SBs in the random boundary network and the low-energy fragments interrupted the connectivity of the random boundaries. In the present $\mathrm{Fe}-\mathrm{Cr}-\mathrm{Mn}-\mathrm{Mo}-\mathrm{N}$ experimental steel, both cases are found, as confirmed by Fig. 10, which shows the metallographs and the corresponding OIM map of the r5\%-a1423K/72 h sample after oxalic acid electrolytic corrosion. SBs created by the impingement of the growing clusters (marked by thick arrows) and the low-energy fragments created by ATs inside the grain cluster (marked by thin arrows) are both observed.

Whether these SBs appearing on the random boundary network are all effective for their interruption and further capable for improving IGC performance, the answer is negative according to the recent experimental findings [5, 44-46]. In the 304 ASS, the research results by Fang et al. [45] showed that $\Sigma 3$ and $50 \%$ of $\Sigma 9$ boundaries displayed a good IGC resistance, but Jones et al. [44] considered that over $97 \%$ of $\Sigma 3$ boundaries and approximately $80 \%$ of $\Sigma 9$ boundaries were immune to sensitization, and $\mathrm{Hu}$ et al. [5] reported that only coherent $\Sigma 3$ boundaries can be called as "special" boundaries for IGC. In the 316 ASS, Laws et al. [46] found a severe chromium-poor phenomenon at $\Sigma 9$ boundaries. In the $\mathrm{Cr}-\mathrm{Mn}-\mathrm{N}$ high-nitrogen and nickel-free ASS, our recent work [9] observed that all $\Sigma 3$ boundaries were immune to IGC; however, similar to the effect of the random boundaries, $\Sigma 5, \Sigma 9$ and $\Sigma 27$ are not resistant to IGC. From the above studies, it can be concluded that "effective SBs" should be varied in different materials and even in the same material. Actually, there are many influencing factors on whether the SBs are effective for IGC resistance [9, 45, 47]. 

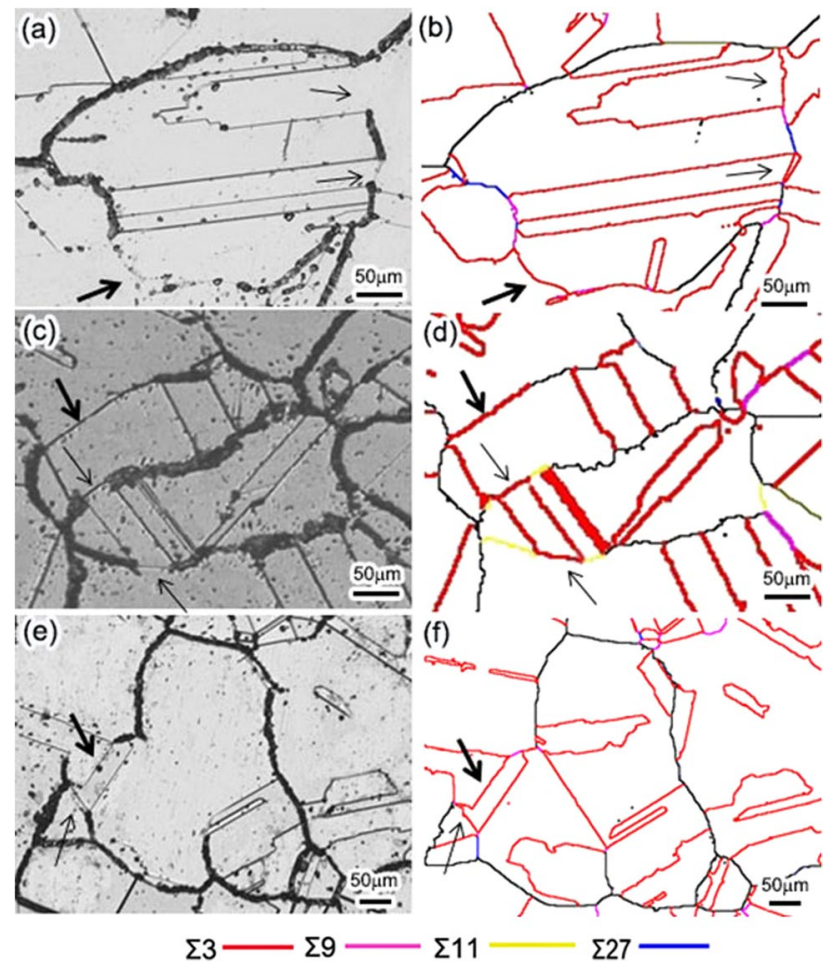

Fig. 10 Metallographs after oxalic acid electrolytic corrosion (a, c, e) and the corresponding grain boundary distributions obtained by EBSD $(\mathbf{b}, \mathbf{d}, \mathbf{f})$ in the $\mathrm{r} 5 \%$-a1423K/72 h sample

According to the comparison of metallograph and the corresponding GBCD in Fig. 10, it can be obviously seen that, like the random boundaries, $\Sigma 9, \Sigma 11$ and $\Sigma 27$ are all not resistant to IGC, whereas all $\Sigma 3$ boundaries, no matter of coherent or non-coherent $\Sigma 3$ boundaries, are immune to IGC. That is to say, only $\Sigma 3$ boundaries in the SBs (the lowenergy fragments), which are formed through the impingement of the growing clusters or created by appearance of annealing twins in the grain cluster, are effective for the improvement of IGC resistance in the experimental steel.

In $\mathrm{Fe}-\mathrm{Cr}-\mathrm{Mn}-\mathrm{N}$ ASS, the precipitates at GBs are only $\mathrm{Cr}_{2} \mathrm{~N}$ phase $[9,23]$, whereas in $\mathrm{Fe}-\mathrm{Cr}-\mathrm{Mn}-\mathrm{Mo}-\mathrm{N}$ ASS, due to addition of Mo element, the precipitates at GBs include an intermetallic phase (i.e., $\chi$ phase) rich in $\mathrm{Cr}$, Mo and $\mathrm{Fe}$ together with $\mathrm{Cr}_{2} \mathrm{~N}$ phase [19]. Precipitation of these two $\mathrm{Cr}$-rich precipitates at GBs will lead to the appearance of the Cr-depleted region near the GBs, causing a severe intergranular corrosion. In $\mathrm{Fe}-\mathrm{Cr}-\mathrm{Mn}-\mathrm{N}$ and $\mathrm{Fe}-\mathrm{Cr}-\mathrm{Mn}-\mathrm{Mo}-\mathrm{N}$ ASSs, only $\Sigma 3$ boundaries are "effective SBs." The previous study of $\mathrm{Fe}-\mathrm{Cr}-\mathrm{Mn}-\mathrm{N}$ ASS [9] has demonstrated that the precipitates are inhibited in the specimen owning a high fraction of $\Sigma 3$ boundaries. Therefore, in the experimental steel, the increase in $\Sigma 3$ boundaries inhibits the precipitation of two kinds of Cr-rich precipitates at GBs, thereby avoiding the appearance of the Cr-depleted zone near the GBs

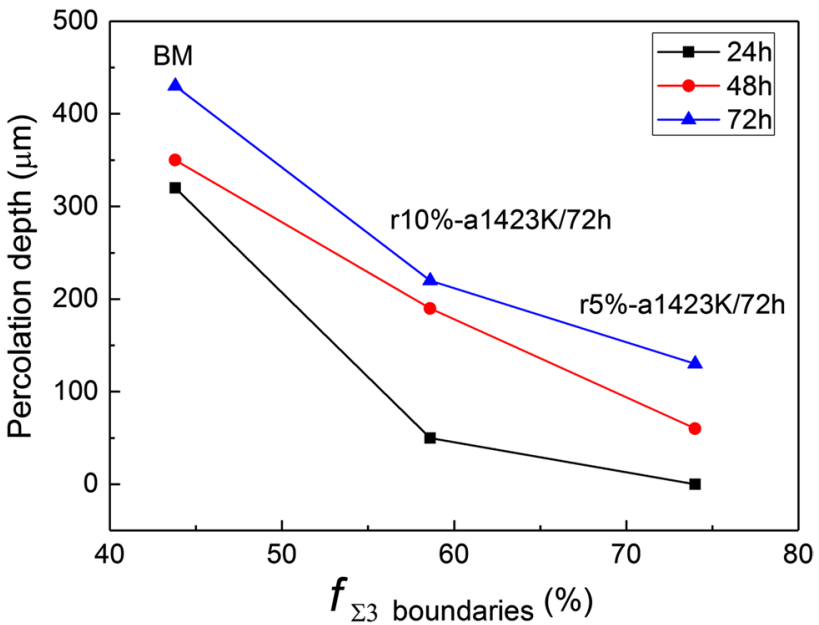

Fig. 11 Percolation depth $v s$. fraction of $\Sigma 3$ boundaries curves for the $\mathrm{BM}, \mathrm{r} 10 \%$-a1423K/72 $\mathrm{h}$ and $\mathrm{r} 5 \%-\mathrm{a} 1423 \mathrm{~K} / 72 \mathrm{~h}$ samples after 24,48 and $72 \mathrm{~h}$ ferric sulfate-sulfuric acid corrosion tests

and improving IGC performance. $\Sigma 9, \Sigma 11$ and $\Sigma 27$ are all not effective boundaries to resist IGC in the experimental steel, since the particularity of the GB is closely related to the GB plane where the GB is located [45]. The special GB determined by the difference in orientation ( $\Sigma$ CSL boundary) can only give 3 of the 5 freedom degrees of the GB plane where the GB is located. Therefore, the most effective criterion should be based on the results of corrosion experiments $[9,45]$.

Figure 11 shows the variation of percolation depth with fraction of $\Sigma 3$ boundaries in these three samples. It can be observed that the penetration depth decreases as the fraction of $\sum 3$ boundaries increases in each testing time. In other words, the IGC resistance becomes better with increasing fraction of $\sum 3$ boundaries.

Figure 12 schematically shows the hindering of IGC penetration from the surface to the interior by $\sum 3$ boundaries distributed in the network of random boundaries. As previously reported [9], in the $\mathrm{Fe}-\mathrm{Cr}-\mathrm{Mn}-\mathrm{N}$ ASS, $\sum 3$ boundaries appeared in the random boundary network were basically created by appearance of ATs in the grain cluster. For the present $\mathrm{Fe}-\mathrm{Cr}-\mathrm{Mn}-\mathrm{Mo}-\mathrm{N}$ ASS, the generation of some $\sum 3$ boundaries (as indicated by thin red lines in Fig. 12) is the same as the case in the $\mathrm{Fe}-\mathrm{Cr}-\mathrm{Mn}-\mathrm{N}$ ASS, but others (as indicated by thick red lines in Fig. 12) are created by the impingement of the growing clusters and the formation of such $\sum 3$ boundaries is governed by the GBE process, e.g., high temperature (1423 K) and long term $(72 \mathrm{~h})$. In the experimental steel, as the annealing time increases, the grain clusters impinge and annex each other, leading to the continuous growth of grain clusters $[34,48]$. The $f_{\mathrm{SBs}}$ increases and the fraction of $\sum 3$ boundaries in SBs also increases with the growth of the clusters, which is the major reason 


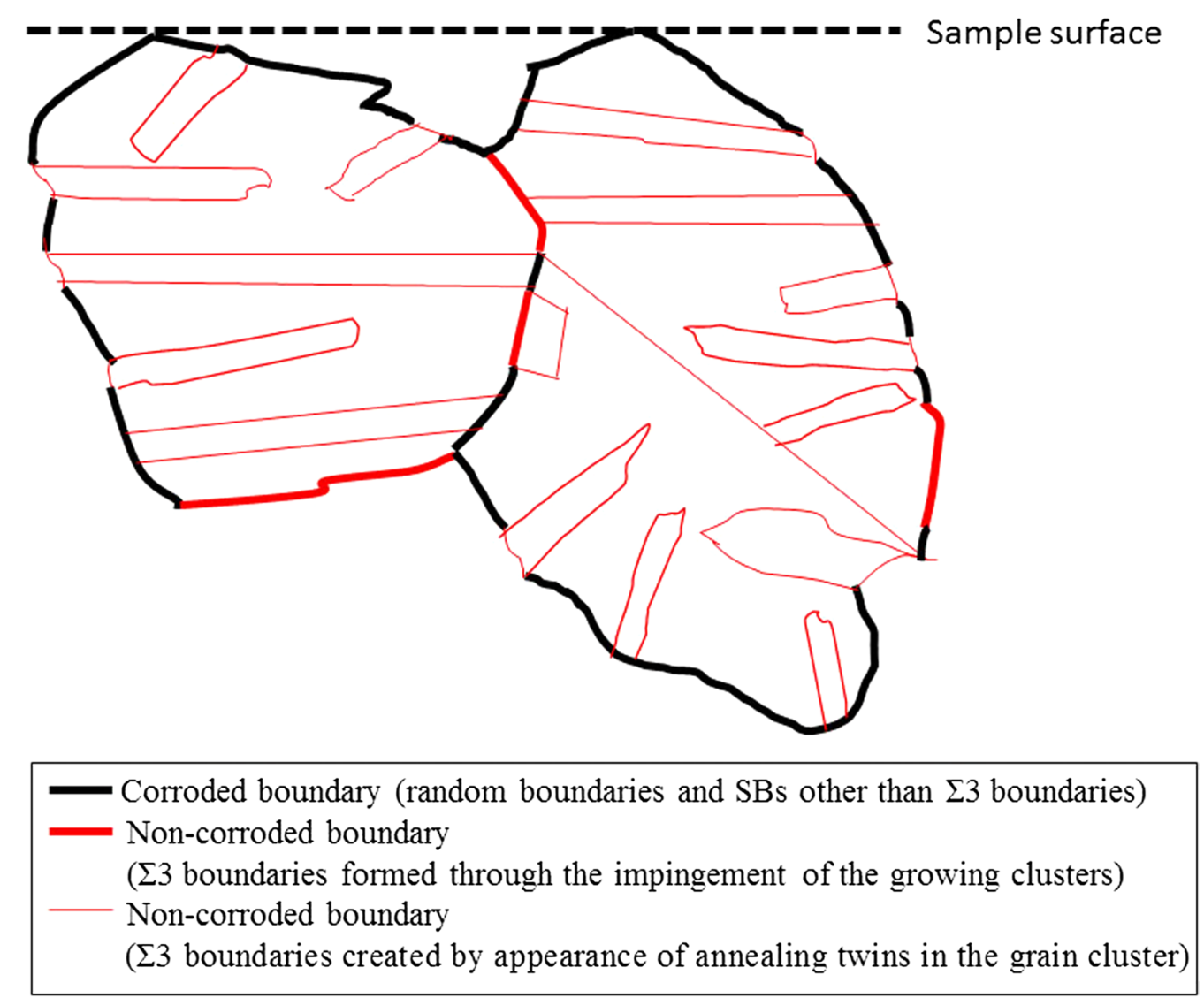

Fig. 12 Schematic diagram showing the hindering of IGC penetration from surface into the interior by $\Sigma 3$ boundaries distributed in random boundary network

for the formation of another $\sum 3$ boundaries different from those in the $\mathrm{Fe}-\mathrm{Cr}-\mathrm{Mn}-\mathrm{N}$ ASS. That is to say, the difference in IGC performance improvement mechanism is mainly due to the different formation mechanisms of ATs in these two steels. As shown in Fig. 12, the $\sum 3$ boundaries (or AT boundaries) produced in the random boundary network by these two ways promote the disconnection of the random boundary network, which hinders the penetration of IGC from surface into the interior and significantly improves IGC resistance of the steel.

\section{Conclusions}

In the present $\mathrm{Fe}-\mathrm{Cr}-\mathrm{Mn}-\mathrm{Mo}-\mathrm{N}$ steel, the proportion of SBs in the sample GBE treated with 5\% cold rolling followed by annealing at $1423 \mathrm{~K}$ for $72 \mathrm{~h}$ reaches $79.4 \%$; there is an increase of $32.1 \%$ compared with that of BM. The $\mathrm{r} 5 \%$-a1423K/72 h sample with the highest fraction of SBs owns the largest size grain cluster. The same as the random boundaries, $\Sigma 9, \Sigma 11$ and $\Sigma 27$ boundaries are not resistant to IGC under this experimental condition. The disconnection of the random boundaries is achieved by the induction of $\Sigma 3$ boundaries in the random boundary network, which hinders the penetration of IGC from surface into the interior and significantly improves IGC resistance of the experimental steel.

Acknowledgements This work was financially supported by the National Natural Science Foundation of China (Grant Nos. 51871048 and 51571058).

\section{References}

[1] T. Watanabe, Res. Mech. 11, 47 (1984)

[2] G. Palumbo, P.J. King, K.T. Aust, U. Erb, P.C. Lichtenberger, Scr. Metall. Mater. 25, 1775 (1991)

[3] M. Shimada, H. Kokawa, Z.J. Wang, Y.S. Sato, I. Karibe, Acta Mater. 50, 2331 (2002)

[4] M. Michiuchi, H. Kokawa, Z.J. Wang, Y.S. Sato, K. Sakai, Acta Mater. 54, 5179 (2006)

[5] C.L. Hu, S. Xia, H. Li, T.G. Liu, B.X. Zhou, W.J. Chen, N. Wang, Corros. Sci. 53, 1880 (2011)

[6] K. Kurihara, H. Kokawa, S. Sato, Y.S. Sato, H.T. Fujii, M. Kawai, J. Mater. Sci. 46, 4270 (2011)

[7] S. Xia, H. Li, T.G. Liu, B.X. Zhou, J. Nucl. Mater. 416, 303 (2011)

[8] S.H. Kim, U. Erb, K.T. Aust, G. Palumbo, Scr. Mater. 44, 835 (2001) 
[9] F. Shi, P.C. Tian, N. Jia, Z.H. Ye, Y. Qi, C.M. Liu, X.W. Li, Corros. Sci. 107, 49 (2016)

[10] T. Watanabe, S. Tsurekawa, Mater. Sci. Eng. A 387-389, 447 (2004)

[11] A. Telang, A.S. Gill, M. Kumar, S. Teysseyre, D. Qian, S.R. Mannava, V.K. Vasudevan, Acta Mater. 113, 180 (2016)

[12] S. Kobayashi, M. Hirata, S. Tsurekawa, T. Watanabe, Procedia Eng. 10, 112 (2011)

[13] Z. Zhuo, S. Xia, Q. Bai, B.X. Zhou, J. Mater. Sci. 53, 2844 (2018)

[14] W.Z. Jin, S. Yang, H. Kokawa, Z.J. Wang, Y.S. Sato, J. Mater. Sci. Technol. 23, 785 (2007)

[15] J.W. Simmons, Mater. Sci. Eng. A 207, 159 (1996)

[16] H. Hänninen, J. Romu, R. Ilola, J. Tervo, A. Laitinen, J. Mater. Process. Technol. 117, 424 (2001)

[17] M.G. Pujar, U.K. Mudali, S.S. Singh, Corros. Sci. 53, 4178 (2011)

[18] H. Baba, T. Kodama, Y. Katada, Corros. Sci. 44, 2393 (2002)

[19] F. Shi, Y. Qi, C.M. Liu, J. Mater. Sci. Technol. 27, 1125 (2011)

[20] F. Shi, L.J. Wang, W.F. Cui, C.M. Liu, J. Iron Steel Res. Int. 15, $72(2008)$

[21] F. Vanderschaeve, R. Taillard, J. Foct, J. Mater. Sci. 30, 6035 (1995)

[22] O. Makoto, H. Kazuo, K. Yasuyuki, S. Masayuki, T. Susumu, ISIJ Int. 42, 1391 (2002)

[23] H.B. Li, Z.H. Jiang, Z.R. Zhang, Y. Cao, Y. Yang, Int. J. Min. Met. Mater. 16, 654 (2009)

[24] R. Beneke, R.F. Sandenbergh, Corros. Sci. 29, 543 (1989)

[25] Y.S. Yoon, H.Y. Ha, T.H. Lee, S. Kim, Corros. Sci. 80, 28 (2014)

[26] K. Alvarez, S.K. Hyun, H. Tsuchiya, S. Fujimoto, H. Nakajima, Corros. Sci. 50, 183 (2008)

[27] H. Kokawa, W.Z. Jin, Z.J. Wang, M. Michiuchi, Y.S. Sato, W. Dong, Y. Katada, Mater. Sci. Forum 539-543, 4962 (2007)
[28] F. Shi, X.W. Li, Y.T. Hu, C. Su, C.M. Liu, Acta Metall. Sin. (Engl. Lett.) 26, 497 (2013)

[29] H.B. Li, Z.H. Jiang, Y. Yang, Y. Cao, Z.R. Zhang, Int. J. Min. Met. Mater. 16, 517 (2009)

[30] H.Y. Ha, T.H. Lee, J.H. Bae, D.W. Chun, Metals 8, 1 (2018)

[31] D.G. Brandon, Acta Metall. 14, 1479 (1966)

[32] F. Shi, X.W. Li, Y. Qi, C.M. Liu, Steel Res. Int. 84, 1034 (2013)

[33] J.B. Lee, Corrosion 39, 469 (1983)

[34] S. Tokita, H. Kokawa, Y.S. Sato, H.T. Fujii, Mater. Charact. 131, 31 (2017)

[35] V. Randle, Acta Metall. Mater. 42, 1769 (1994)

[36] B.W. Reed, M. Kumar, Scr. Mater. 54, 1029 (2006)

[37] Q.Y. Li, J.R. Cahoon, N.L. Richards, Mater. Sci. Eng. A 527, 263 (2009)

[38] W. Wang, F. Brisset, A.L. Helbert, D. Solas, I. Drouelle, M.H. Mathon, T. Baudin, Mater. Sci. Eng. A 589, 112 (2014)

[39] X.J. Guan, F. Shi, H.M. Ji, X.W. Li, Mater. Sci. Eng. A 765, 138299 (2019)

[40] J. Kim, M. Kwon, B.C. De Cooman, Acta Mater. 141, 444 (2017)

[41] X.W. Li, X.M. Wu, Z.G. Wang, Y. Umakoshi, Metall. Mater. Trans. A 34, 307 (2003)

[42] Q.X. Dai, A.D. Wang, X.N. Cheng, J. Iron Steel Res. 14, 34 (2002)

[43] V. Gavriljuk, Yu. Petrov, B. Shanina, Scr. Mater. 55, 537 (2006)

[44] R. Jones, V. Randle, Mater. Sci. Eng. A 527, 4275 (2010)

[45] X.Y. Fang, Ph.D. thesis, Shanghai University (2008)

[46] M.S. Laws, P.J. Goodhew, Acta Metall. Mater. 39, 1525 (1991)

[47] V. Randle, Scr. Mater. 54, 1011 (2006)

[48] C.M. Barr, A.C. Leff, R.W. Demott, R.D. Doherty, M.L. Taheri, Acta Mater. 144, 281 (2018) 